\title{
Correspondence
}

\section{Palace and Pollution}

SIR,-I was disappointed at the lack of sympathy displayed in your article entitled "Palace and Pollution" (Nature, 228, 398; 1970), for the various causes being argued at "The Countryside in 1970 " symposium.

It is surely hardly realistic to expect such a meeting to resolve conflicts of amenity and economic interests; though you are right to point out that practical measures must take account of the wishes of people to exploit the environment for short term sectional advantages.

In view of the prestige which Nature enjoys, I am sorry that your contributor felt obliged to suggest that the Duke of Edinburgh was probably misguided to pub. licize the view that more people lead to a meaner life for all, and I am depressed by your calm acceptance that a population rise to 70 millions in Britain is inevitable. This will be the case only if nothing is done to avoid it. The Duke of Edinburgh suggested that population growth would be much slower and might be arrested if unwanted children were never born. This is a matter of the will to encourage people to take contraceptive measures and to make the means freely available, a matter about which the Duke surely displayed greater wisdom than your contributor.

\section{Yours faithfully,}

\section{Collingham Green, \\ Little Sutton, Wirral, \\ Cheshire L66 4 NX.}

SIR,--In your comment on the "Countryside in 1970" conference (Nature, 228, 398; 1970) you rightly draw attention to the glossing over of the relationship between the spread of affluence and environmental destruction. However, you appear to consider that this must be accepted and do not mention the other alternative to the unacceptable maintenance of inequality: the levelling down of material consumption. This may seem more desirable than the alternative you describe: the growth of population beyond 70 million, since you say that it would be unjust (to whom ?) to keep it down, and the reduction of large parts of the countryside of south-east England to "isolated pockets of greenery". Do you really believe that we should pursue our immediate ends in this way with no thought for the future?

Yours faithfully,

\section{John Davoli}

Chairman of the Conservation Society,

10 Broadlands Avenue,

Shepperton,

Middlesex.

\section{Nuclear Tests and Earthquakes}

Sir,--I agree with Newstead and Pile ${ }^{1}$, that tho French test on May 24, 1970, was unlikely to have "triggered" the Peruvian earthquake. It was this coincidenco, however, that focused press attention on the possible connexion between bomb tests and earthquakes. I do not agree that atmospheric tests are necessarily poorly coupled to the ground, especially when conducted over water $^{2}$, nor are time delays unreasonable. Delays of many days in the build-up of seismic activity often occur near test sites and in one instance a zone of $40 \mathrm{~km}$ from ground zero was active following a test ${ }^{3}$. Whatever the mechanism might be, such delays do occur.

The frequent incidence of fairly large earthquakes in Peru is simply a measure of the seismic instability of the region. Bomb tests adjacent to such regions must remain suspect until proved harmless. The possibility of a connexion between the tests and the Peruvian earthquake cannot be dismissed by means of statistics applying to other areas.

Statistical arguments by Emiliani et al. ${ }^{4}$, similar to those of Newstead and Pile, have shown a correlation between underground tests and distant earthquakes. Later work ${ }^{5}$ has shown no such correlation. In all cases, clata from bombs of all sizes and earthquakes of all sizes were used. I am unaware of any detailed analysis of large bomb tests. It is here that correlations might be expected to show, if they exist.

Healy and Marshall ${ }^{5}$ do give a table of eleven tests with a yield of over 200 kilotons. They give the number of earthquakes recorded in 24 hour periods before and after the tests. There were five in the periods before and sixteen afterwards.

Twelve of the post bomb earthquakes were after the Stones and Bilby tests. These were the second and third tests, and the authors say that this abnormal activity "may have been contemporaneous with natural aftershocks". The measurements were made in a circle of $860 \mathrm{~km}$ radius around the Nevada test site. Whether or not there were effects further afield is not known. The comparatively large effects after early tests, if indeed they were not natural, lend some support to the original proposal of Emiliani et al. ${ }^{4}$. It is possible that some seismic stresses were relieved by the early tests so that later ones occurred in a more stable environment.

Further information about the Bilby test is contained in a paper by Archambeau and Sammis ${ }^{6}$. In Figs. 6 and 7 , they show a best fit between their theory and the measured values of particle velocity. Fig. 6 is for the Rayleigh wave of period $20 \mathrm{~s}$ and Fig. 7 is for the Love wave of the same period. In both cases there are anomalously high values towards the east coast of the United States. These can be attributed to an anomalously high main field or to a separate disturbance. In the case of the Love wave there is also an anomaly to the northeast, on the Canadian border. It would be interesting to sec similar data for other tests.

Archambeau and Sammis also show the contribution of seismic energy to the total energy released in an underground test. The question to answer is whether this release of seismic energy is restricted to the immediate neighbourhood of the source or not.

\section{Yours faithfully,}

\section{David S. RoBertson.}

"Maroonika",

Milan Terrace,

Stirling, SA 5152.

${ }^{1}$ Newstead, G., and Pile, M., Nature, 227, 317 (1970).

${ }^{2}$ Harkrider, D. G., Reviews of Geophysics and Space Physics, 8, 501 (1970).

${ }^{3}$ Hamilton, R. M., McKeown, F. A., and Healy, J. H., Science, 166, 601 (1969).

4 Emiliani, C. Harrison, C. G. A., and Swanson, M. Science, 165, 1255 (1969).

${ }^{5}$ Healy, J. H., and Marshall, P. A., Science, 169, 176 (1970). Archambeau, C., and Sammis, C., Reviews of Geophysics and Space Physics,
$\mathbf{8 , 4 7 3}(1970)$. 